\title{
Vergifnis ter wille van JHWH se Naam (Ps 25:11)
}

\author{
D F O'Kennedy \\ Departement Ou en Nuwe Testament \\ Universiteit van Stellenbosch
}

\begin{abstract}
Forgiveness for the sake of YHWH's Name (Ps 25:11)

This article investigates the concept of divine forgiveness as illustrated in Psalm 25, especially verse 11. Psalm 25:11 is one of only four references in the Psalms where the Hebrew stem סלח (forgive is found). Scholars agree that the petition for forgiveness in verse 11 forms the core or centre of the entire Psalm. This article will offer a possible answer to the following question: what motivates the supplicant to ask for forgiveness? In contrast to other forgiveness passages the Psalmist does not regard repentance or obedience as motivation for the petition. He rather emphasizes the fact that his sin is great ( $v$ 11b). The true motivation for this prayer for forgiveness lies in the Name and honor of YHWH (v 11a). He experienced YHWH as 'n faithful God in the past; therefore he has the courage and honesty to plea for forgiveness.
\end{abstract}

\section{INLEIDING}

McKeating (1965:69) skryf die volgende oor Goddelike vergifnis in die Psalms:

The psalmists in general are by no means preoccupied with sin and forgiveness. The number of explicit references to the forgiveness of God is very small. Indeed, if we were to confine our attention to such explicit statements we should miss none of any weight were we to examine only five particular psalms $(25,32,51,103$ en 130)

McKeating se stelling oor die frekwensie van vergifnis in die Psalms is debatteerbaar aangesien daar talle ander verwysings na sonde en vergifnis in die Psalms is (bv Ps 19:13; 41:4-5; 65:4; 85:3; 86:5, 15; 78:38; 79:8-9; 99:8; $106: 1,6-8$; e a). Twee sake wat hy wel beklemtoon is dat die bestudering van vergifnis in die Psalms nie afgeskeep mag word nie en dat Psalm 25 hierin 'n sentrale rol vervul. 
Verskillende terme en uitdrukkings word gebruik om Goddelike vergifnis te beskryf. Geleerdes stem egter saam dat die konsep vergifnis in die $\mathrm{Ou}$ Testament die beste deur die term סלח uitgedruk word. Dit kom uitsluitlik met God as subjek voor en word slegs met betrekking tot vergifnis gebruik (Stamm 1940:47; Hausmann 1986:860; Kselman 1992:831; Olivier 1997:259-264). In drie van McKeating (1965:69) se vergifnis Psalms word die werkwoord סלח aangetref (Ps 25:11; 103:3; 130:4). Die byvoeglike naamwoord en hapax legomenon סלח (vergewensgesind, bereid om te vergewe) kom in Psalm 86:5 voor.

Die bestudering van die vyftig סלח-verwysings wys daarop dat die verstaan van vergifnis in die Ou Testament verskillende fasette het (vgl O'Kennedy \& Olivier 1996:496-508). Verskillende motiverings word byvoorbeeld gegee hoekom God moet vergewe. In hierdie artikel word 'n moontlike antwoord verskaf op die vraag: Wat motiveer die bidder om te smeek vir vergifnis? Die doel van hierdie artikel is nié om Psalm 25 in diepte te bestudeer nie; gevolglik word al die literêre- en historiese kwessies nie in soveel detail bespreek nie. Psalm 25 word vanuit die hoek van die Goddelike vergifnis ${ }^{1}$ bestudeer en die skopus van die artikel lê in afdeling 3. Daar gaan wel enkele opmerkings oor die literêre- en historiese dimensie gemaak word, omdat die teologiese dimensie nie in isolasie nagevors kan word nie.

\section{LITERÊRE EN HISTORIESE DIMENSIE}

\subsection{Psalms as gebedsliteratuur}

'n Groot gedeelte van die 150 Psalms kan as gebedsliteratuur getipeer word; gebede wat in 'n hele aantal literêre vorme of Gattungen uitgedruk word (Louw 1979:98-103; Greenberg 1983:7). In die Psalms is daar 'n direkte verband tussen gebede, liedere en poësie. Baie gebede is in poëtiese taal geskryf en kan in sommige gevalle ook as liedere getipeer word (Westermann 1989:1-3).

In teenstelling met die narratiewe is die Psalms nie direk van hulle literêre konteks afhanklik nie. Die Psalms is "algemene" gebede en kan in verskillende literêre kontekste inpas (Corvin 1973:50-51). By die bespreking van die Psalms is daar nie veel probleme ${ }^{2}$ met die afbakening nie, omdat hulle alreeds in verskillende Psalms ingedeel is. Om hierdie redes sal daar nie

\footnotetext{
${ }^{1}$ Die skrywer kon geen ander bron vind waarin Psalm 25 spesifiek vanuit hierdie hoek bestudeer is nie. McKeating (1965:73, 80-81) bied wel 'n kort bespreking van Ps 25 saam met ander vergifnis Psalms.

${ }^{2}$ Daar is wel sommige Psalms wat in samehang met mekaar bestudeer moet word soos bv. Ps 1/2, 9/10 en 42/43. Die Psalms waarin die term סלח voorkom (Ps 25, 86, 103, 130) lewer nie sulke probleme op nie.
} 
by Psalm 25 aan die "literêre konteks en afbakening" aandag verleen word nie.

Daar is 'n direkte verband tussen die gebruik van die Hebreeuse woord סלח (vergewe) en gebedsliteratuur. Vergifnis kan waarskynlik die beste verstaan word as dit in die gebedsliteratuur nagevors word. Een en twintig סלח-verwysings kom in Ou-Testamentiese gebede ${ }^{3}$ voor en daar is drie ander teksgedeeltes wat indirek na gebed of die antwoord op 'n gebed verwys ( $\mathrm{vgl}$ Num 14:20; 2 Kon 5:18 [2x]; en 2 Kron 7:14) (Kselman 1992:831; O'Kennedy \& Olivier 1996:499-501). Psalm 25:11 kan gevolglik nie los van die ander סלחgebede bestudeer word nie.

Psalm 25 vorm deel van die eerste bundel van die Psalter (Ps 1-41), die sogenaamde Dawidsbundel. Alhoewel hierdie as 'n unieke Psalm beskou word, meld Freedman (1992:125-138) dat daar duidelike ooreenkomste tussen Psalm 25 en 34 is. Hierdie ooreenkomste het meer te make met die poëtiese struktuur as met die teologiese inhoud.

\subsection{Vertaling en tekskritiek}

Daar is geen groot tekskritiese probleme in Psalm 25:11 nie en die tekskritiese apparaat van BHS bied geen alternatiewe vertalingsmoontlikheid nie. Die vers kan waarskynlik soos volg vertaal word: "Ter wille van u Naam, $\mathrm{JHWH},{ }^{4}$ vergewe asseblief my ongeregtigheid (עון), want dit is baie" (Eie vertaling). ${ }^{5}$

Die waw wat in vers 11 gebruik word moet waarskynlik as 'n emfatiese waw beskou word. Die vertaling is dus "vergewe asseblief" (Craigie 1983:216217). Hierdie beklemtoning word verder onderstreep deurdat die bidder in vers 11 direk met God praat, terwyl daar in verse 8-10 en 12-15 oor God gepraat word. Volgens Van der Lugt (2006:271) sluit vers 11 die einde van strofe 1 emfaties af.

Die bekende Hebreeuse term עון word op verskillende maniere in vers 11 vertaal: "guilt" (NRSV; RSV); "debt" (Kraus 1993:318); "sins" of "sonde" (1983-AV; TEV;); "wickedness" (NEB); "iniquity" of "ongeregtigheid" (1933/53AV; NIV; Terrien 2003:251); "transgression, sin" (KBL); "Verkehrtheit" of fout (Knierim 1976:243; Schultz 1981:650). Al die verskillende woorde vir sonde is

\footnotetext{
${ }^{3}$ Vgl Eks 34:9; Num 14:19; 1 Kon 8:30, 34, 36, 39 en 50; 2 Kron 6:21, 25, 27, 30 en 39; Neh 9:17; Ps 25:11; 86:5; 103:3; 130:4; Klaagl 3:42; Dan 9:9 en 19; en Am 7:2.

${ }^{4}$ Die spelling YHWH kan ook gebruik as vertaling of transkribering van die Hebreeus יהוה en soos algemeen in Engels voorkom. Die Afrikaanse spelling JHWH word verkies aangesien dit in onlangse uitgawes van HTS gebruik is (vgl HTS 62/2).

${ }^{5}$ Daar word vanuit die 1933/53 AV aangehaal tensy anders vermeld.
} 
'n moontlikheid, maar waarskynlik moet die selfstandige naamwoord עון met "ongeregtigheid, fout of verkeerde gedrag" vertaal word. Die Hebreeuse woord רשע kan eerder met "skuld" vertaal word en nie die woord עון nie.

Sommige Engelse vertalings (bv NRSV en RSV) vertaal die werkwoord סלח met "pardon" (kwytskeld, begenadig, vergewe). Die Hebreeuse werkwoord סלח het 'n sterk betekenis en "forgive" of "vergewe" is die beste vertalingsmoontlikheid. Die 1983-Afrikaanse vertaling vertaal al die סלחverwysings in die gebedsliteratuur met vergewe, vergeef of vergifnis.

Die Hebreeuse woord רב se primêre betekenis is waarskynlik "baie" (many, much, numerous, plentiful, abounding). Hierdie woord dra egter ook die betekenis van "groot" (great, important) oor (vgl 1933/53-AV; 1983-AV; KJV; NASB; NEB; NIV; NRSV). Dit is moeilik om 'n keuse te maak en die primêre betekenis word gekies.

\subsection{Opbou en struktuur}

Aangesien Psalm 25 'n akrostiese lied ${ }^{6}$ is, is dit moeilik om die struktuur van die Psalm te bepaal. Daar is ook 'n paar wysigings in die akrostiese struktuur. In die Masoretiese teks is daar geen verse wat met die letters i en p begin nie, terwyl daar twee verse is wat met $\Xi$ (vv 16, 22), en twee verse wat met die letter $า(v 18,19)$ begin (Anderson 1977:206; Kraus 1993:319). Geleerdes verskil oor die verdeling van die Psalm. 'n Moontlike voorstel is as volg:"

- Opskrif en belydenis van vertroue

- Eerste smeking

- Tweede smeking

- Lof (himniese gedeelte)

- Derde (sentrale) smeking

- Versekering en vermaning

- Vierde smeking

- Vyfde smeking

Ruppert (1972:576) ${ }^{8}$ wys op 'n spesifieke chiastiese struktuur van die Psalm: a (1-3); b (4-7); c (8-10); d (11); c' (12-14); b' (15-18); a' (19-21). Alhoewel

\footnotetext{
${ }^{6}$ Akrosties beteken dat die Psalm so gestruktureer is dat die verse met opeenvolgende letters van die Hebreeuse alfabet begin.

${ }^{7}$ Vgl Ruppert (1972:576-577); Gerstenberger (1988:120); Bratcher \& Reyburn (1991:244). Sien ook Van der Lugt (2006:267-268) se volledige opsomming van die tientalle verdelings wat deur geleerdes voorgestel word.

${ }^{8}$ Möller (1932:252) wys ook op 'n chiastiese struktuur, maar sy verdeling verskil van Ruppert s'n: a (1); b (2-3); c (4-7); d (8-11); d' (12-15); c' (16-19); b' (20-21); a' (22).
} 
daar geredelik by Ruppert aangesluit kan word, word die gebed eerder in vyf smekings verdeel.

Ruppert se struktuur maak gebruik van die herhaling van woorde en frases in die Psalm: אל-אבוש "laat my nie beskaamd staan nie" (vv 2, 20); קוה

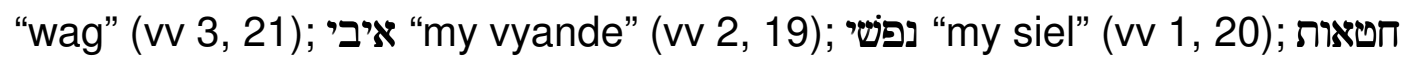
"sonde" (vv 7, 18); טוב "goed, voorspoed" (vv 8, 13); יורה "wys, leer" (vv 8, 12); בררך". בריתו "sy verbond" (vv 10, 14). Die herhalings beklemtoon die sentrale plek van die onderrig van die Here se weë wat veral in die wysheidsliteratuur voorkom (Ridderbos 1962:261; Craigie 1983:218).

Geleerdes verskil oor die verdeling van die Psalm, maar stem saam dat vers 11 'n sentrale rol in die struktuur van die hele Psalm vervul. Die smeking om vergifnis ( $v 11)$ is letterlik in die middel van die Psalm (22 verse) en kan as middelpunt of kern van die gebed beskou word. Die tema van vergifnis word in die tweede (vv 4-7) en vierde smeekbedes (vv 16-18) herhaal (Ruppert 1972:579; Bratcher \& Reyburn 1991:244-245; Freedman 1992:129; Human 1994:93; Terrien 2003:253; Van der Lugt 2006:272).

Verskillende terme en frases word in die Psalm gebruik om die Goddelike vergifnis te beskryf:

- Nie dink aan my sondes nie (v 7): לא זכר

- Vergewe (v 11): סלח

- Sien my in genade aan (

- Vergewe (v 18):

Die verwysings na JHWH se רחם (barmhartigheid), חסד (troue liefde) en פדר (goedheid) asook die bidder se חטאת (sonde) en פשע (opstand, oortreding) in verse 6 en 7 antisipeer die teologiese kern in vers 11 (McCann 1996:778).

\subsection{Gattung}

Daar is reeds vermeld dat Psalm 25 'n akrostiese lied is wat met die volgende ander akrostiese Psalms vergelyk kan word: Psalm 9-10; 34; 37; 111; 112; 119; en 145 (Graigie 1983:128; Terrien 2003:253).

Gunkel (1975:172) en die meeste ander geleerdes ${ }^{9}$ tipeer Psalm 25 as 'n klaaglied van die enkeling. Hierdie klaaglied kan egter nie in 'n vaste patroon gegiet word nie. Naas die bede en wense in verse 1-7, 11 en 16-22

\footnotetext{
${ }^{9}$ Vgl Human (1996:87).
} 
vind 'n mens ook "abgedämpfte Töne des Hymnus" (vv 8-10) en elemente van die wysheidspoësie (Ruppert 1972:578). ${ }^{10}$

Volgens Gerstenberger (1988:120-121) vertoon Psalm 25 elemente van 'n individuele klaaglied; tog reken hy dat dit eerder 'n klaaglied van die volk is wat ontstaan het uit 'n ouer individuele klaaglied. Alhoewel Psalm 25 onder die breë kategorie "klaaglied van die enkeling" geplaas kan word, moet ons erken dat daar nie 'n groot skeiding is tussen die enkeling en die enkeling wat deel is van die volk of gemeenskap nie (vgl 2.5). In die lig van die teologiese inhoud van die Psalm (vgl punt 3) kan die klaaglied moontlik as 'n “"n gebed van vertroue" of "gebed om hulp" getipeer word (Craigie 1983:217; Mays 1994:125). ${ }^{11}$

\subsection{Sitz im Leben}

Weiser (1965:238) reken dat Psalm 25 by die Verbondsfees voorgedra is, terwyl Croft $(1987: 68,125)$ beweer dat dit 'n na-eksiliese liturgie vir 'n vasdag is. Croft wys verder daarop dat die bidder nie 'n koning is nie, maar eerder 'n leier wat vir homself en vir die volk bid.

Volgens Gerstenberger (1988:121) dui die vorm en inhoud op gemeenskaplike aanbidding. Die gemeenskap is duidelik nie meer 'n clan of familiegroep nie, maar die plaaslike bymekaarkoms van gelowige Jode. Die emosies en hoop van die individu word aangespreek in die aanbidding van die gemeenskap.

Weiser en Croft se voorstelle oor 'n spesifieke fees of vasdag is moontlik, maar Psalm 25 bied geen spesifieke getuienis met betrekking tot offers of enige ander versoeningsritueel nie (McKeating 1965:82).

Gerstenberger se siening beklemtoon weer dat 'n mens nie die klaaglied van die enkeling los van die gemeenskap kan bestudeer nie. In die lig van Weiser, Croft en Gerstenberger se standpunte kan aanvaar word dat die Psalm nie slegs oor 'n individu handel nie.

Die moontlikheid bestaan ook dat 'n mens hier met gebedsliteratuur te doen het wat deur die latere wysheid beïnvloed is. Heelwat van die gebedsformules is waarskynlik aan die Psalms (veral Ps 37) ontleen (Ruppert (1972:582).

Ten spyte van onduidelikheid oor die presiese kultiese Sitz im Leben is daar drie sake wat in die Psalm na vore kom:

\footnotetext{
${ }^{10}$ Möller (1932:253) tipeer die eerste helfte van die gebed as volg: v 4-7 (klag); v 8-10 (himne); v 11 (uiting van vertroue).

${ }^{11}$ Die Psalm word ook getipeer as 'n geestelike gebed, 'n gebedslied, gebed van die gemeente, didaktiese psalm, wysheidspsalm, ens (vgl Human 1996:79-80).
} 
- Die bidder verkeer in groot nood. Hy weet waarskynlik dat hy omring word deur verskillende vyande wat hom haat (vv 2, 15, 17, 19). Hy gebruik ook uitdrukkinge van 'n man wat "valslik aangekla" word (v 21).

- Tweedens weet die bidder dat hy skuldig is ( $v 8)$ en hy bid om vergifnis van sonde (vv 7, 11, 18). Hy soek toevlug of "asiel" by JHWH ( $(20)$.

- Psalm 25 weerspieël ook die gebed van 'n Godvresende man wat op die pad van die Here wil wandel (vv 4, 12) (Beyerlin 1970:22; Kraus 1993:319320).

\subsection{Samestelling, redaksie en datering}

Die enigste literêr-kritiese en redaksie-historiese probleem word in vers 22 aangetref. Vers 22 pas nie in die alfabetiese (akrostiese) struktuur van die res van die Psalm nie. Dit is waarskynlik 'n latere byvoeging wat die klem op die volk Israel laat val (Van Uchelen 1979:170; Kraus 1993:319).

Psalm 25 moet laat gedateer word, waarskynlik in die na-eksiliese tyd (Fohrer 1968:287; Kraus 1988:319). ${ }^{12}$ Die gebruik van die uitdrukking in vers 11 "Ter wille van $U$ Naam" versterk die gedagte van 'n latere datering. Dit is ' $n$ belangrike uitdrukking wat in die tyd van die Deuteronomis en daarna gebruik is. In die na-eksiliese gemeenskap is daar dikwels tot JHWH se Naam gebid (Eichrodt 1967:310; Weinfeld 1972:192-193). Die gebruik van 'n akrostiese struktuur dien as verdere bewys vir 'n na-eksiliese datering (Anderson 1977:207). 'n Laaste motivering vir ' $n$ laat datering is die bidder se gebruik van talle ander Ou-Testamentiese motiewe, beelde en verwysings. Temas en uitdrukkings van die kultus is verweef met elemente van die wysheidstradisie, ${ }^{13}$ die Pentateug (veral Eks 32-34) en die Deuteronomistiese geskiedwerk. Volgens Human (1996:86) kan ons werklik praat van die kanoniese profiel van Psalm 25, omdat daar motiewe van die Wet, Profete en Geskrifte hierin voorkom.

\footnotetext{
${ }^{12}$ In teenstelling met die meeste geleerdes dateer Terrien (2003:257) die Psalm kort voor die Babiloniese ballingskap en verwoesting van die tempel in 586/7 vC.

${ }^{13}$ Brueggemann (1991:63-92) wys daarop dat die eenvoudige "torah-piety" van 'n wysheidspsalm soos Ps 1 bevraagteken en opgelos word in die klaagliedere en lofliedere. Volgens hom is Ps 25 'n goeie voorbeeld van so 'n Psalm wat verby die "torah-piety" beweeg.
} 


\section{TEOLOGIESE DIMENSIE VAN VERGIFNIS}

\subsection{Die verstaan van vergifnis in Psalm 25}

Die struktuur van Psalm 25 en die verskillende terme vir vergifnis toon aan dat vergifnis 'n sentrale konsep in hierdie Psalm is. Enkele aspekte van hierdie konsep sal vervolgens uitgelig word.

In Psalm 25 leer 'n mens die twee "partye" in die gebed om vergifnis ken, naamlik die bidder en God. Die volgende "eienskappe" kan aan die bidder toegeken word: iemand wat op die Here vertrou (vv 1-3, 5, 21); 'n persoon in nood ( $v v 2,17,19,20)$; 'n persoon wat op die pad van die Here wil wandel (vv 4-5, 12); 'n sondaar wat skuldig voor God staan (vv 7, 8, 11, 18). Die bidder besef ook dat hoop, redding en vergifnis slegs by God lê (vv 1-2, 5, $11,16,18,20)$. JHWH is ' $n$ God wat Hom alreeds in die geskiedenis bewys het $(v v 3,6,8,9,10,14)$ en gevolglik kan vergewe.

Die tweede gedeelte van vers 11 sê: "vergewe asseblief my ongeregtigheid, want dit is baie". In teenstelling met sommige ander vergifnisgedeeltes in die Ou Testament ( $v g l 1$ Kon 8:33, 47-48; Ps 86) beskou die bidder nie sy eie of die volk se berou as grondrede vir die smeking om Goddelike vergifnis nie. Die bidder van Psalm 25 wys eerder op sy baie of groot sondes. Ridderbos (1955:220) glo dat die verwysing na die groot ongeregtigheid van die bidder nie dien as grond vir die gebed om vergifnis nie, maar wel as 'n rede om met groter dringendheid te vra. 'n Mens kan by Ridderbos aansluit en beklemtoon dat daar eintlik geen menslike rede is hoekom JHWH moet vergewe nie. JHWH vergewe, omdat Hy 'n genadige God is en uit vrye wil so besluit. Aan die ander kant moet ons beklemtoon dat die bidder wel die reg het om met dringendheid te vra en enige motivering mag aanbied. Eerlikheid is 'n kenmerk van die Ou-Testamentiese gebede; daarom word daar nie net gepleit om vergifnis nie, maar ook redes aangebied. Die motivering/s wat in vers 11 aangebied word is die beste waaraan die bidder op daardie stadium kon dink.

Die beweegrede in Psalm 25:16-18 sluit indirek aan by die "baie sondes" van die volk in vers $11 \mathrm{~b}$. In hierdie verse word om vergifnis gesmeek vanweë die ellende, swaarkry en nood van die bidder. Dit is onseker of die bidder glo dat sy baie sondes die oorsaak van sy swaarkry is. Die teks van Psalm 25 verwys nie direk na so 'n oorsaak (sonde) en gevolg (nood) nie. Daar word eerder verwys na die vyande (vv 2 en 19) as die oorsaak van sy nood. Ons kan tot die gevolgtrekking kom dat vers $11 \mathrm{~b}$ asook verse 16-18 fokus op die mens se onvermoë en kleinheid om enigiets self te doen. Hy is sondig, eensaam, magteloos en in nood. 
Daar is ook ander סלח-gebede waar die groot sonde/s van die volk as motivering vir vergifnis aangebied word: die hardkoppigheid en opstandigheid van die volk (Eks 34:9; ${ }^{14}$ Neh 9:16-18, 26-29); die sondes van die leiers (Dan 9:8-9); en die nietigheid van die volk (Am 7:2) (O’Kennedy \& Olivier 1996:506).

Volgens Psalm 25 is vergifnis nie net die kwytskelding van skuld nie; dit handel oor God se onbegrensde liefde. Ware vergifnis bevat die saad van 'n ewige verbond wanneer Goddelike beloftes geskryf word op die hart van 'n nuwe mens (Jer 31:33-34). Die teologie van die verbond word ingeënt op die teologie van die Naam (Terrien 2003:256). Die God wat homself JHWH noem is die Een wat bereid is om te vergewe en nuut te maak. Psalm 25 beklemtoon hierdie duidelike verband tussen vergifnis en 'n nuwe lewe ( $v v 4$, 5, 9, 12 en 21). Hierdie nuwe lewe behels dat die bidder op JHWH se weë kan wandel (Kraus 1993:323; Mays 1994:127).

Vers 11 asook verse 16-18 veronderstel dat genade en vergifnis 'n fisiese ingrype van God sal wees. In verse 17 en 18 veronderstel die bidder dat die bewys van vergifnis 'n fisiese resultaat en nie net 'n geestelike resultaat sal hê nie (McKeating 1965:73): "Ek verkeer in die allergrootste nood; bevry my tog uit my ellende. Kyk hoe sleg gaan dit met my en hoe swaar kry ek. Vergewe (נשטא) tog al my sondes."

Verskeie ander סלח-gebede wys op hierdie fisiese bewys van God se vergifnis: terugkeer vanuit Ballingskap (1 Kon 8:34); skenk van reën (1 Kon 8:36); bevryding van peste en plae (1 Kon 8:39); genesing van siekte en red van die dood (Ps 103:3); stop van sprinkaanplaag en vuur (Am 7:1-6).

In Psalm 25 is daar 'n geneigdheid om JHWH te vertrou, maar ook 'n bewustheid dat "alles nie reg is nie." Die bidder in nood vra ernstige vrae oor JHWH se verbondstrou of troue liefde (חסד). Die eerlike klag roep die volgende vrae op: Is JHWH getrou? Is sy woord betroubaar? Is gehoorsaamheid regtig belangrik? (Brueggemann 1991:73-74). Hierdie eerlikheid veroorsaak 'n spanning in die hart van die bidder sowel as die leser, veral as ' $n$ mens die inhoud van die verse direk rondom vers 11 bestudeer (vv 10 en 12-14). Verse 10 en 12-14 ${ }^{15}$ beklemtoon die goedheid, trou en seën van JHWH vir dié wat getrou is aan die bepalings van sy verbond en Hom dien. In teenstelling met hierdie vroom belydenis beklemtoon die bidder in

\footnotetext{
${ }^{14}$ Human (1994:94; 1996:80-81) wys op die ooreenkomste tussen Ps 25 en die optekening van die verbondsvernuwing in Eks 32-34. Die Psalmis smeek om vergifnis, omdat hy bewus is van die gebeure wat beskryf is Eks $32-34$ sowel as die openbaring van God aan Moses (Eks 3:14-16).

${ }^{15}$ Verse 12-14 vertoon raakpunte met die retribusieleer. Dit is veral die positiewe faset van retribusie wat aandag geniet, dit wil sê as iemand die Here dien, sal hy voorspoed geniet (Kuntz 1977:232).
} 
vers $11 \mathrm{~b}$ dat hy juis nie gehoorsaam aan die verbond is nie (McCann 1996:778). Die vraag is of hy reken dat JHWH net dié sal vergewe wat gehoorsaam is aan sy verbond en of hy glo dat JHWH enige sondaar kan vergewe. ' $n$ Verder vraag is of hy glo dat JHWH' $n$ getroue verbondsgod is. Die feit dat die bidder wel om vergifnis smeek beklemtoon sy geloof in JHWH as die enigste Een wat kan vergewe, maak nie saak hoe baie sy sondes is nie. Hy beroep hom op JHWH se genade, trou en vergewensgesindheid.

\subsection{Ter wille van JHWH se Naam}

In die Ou Testament vind ons verskeie motiverings hoekom God moet vergewe. Daar is reeds in die vorige afdeling verwys na berou en gehoorsaamheid asook die baie sondes en nood van die volk as beweegredes. Die volgende redes word ook in die סלח-gebede vermeld: sodat die volk vir God kan dien/vrees (1 Kon 8:40; Ps 130:4); God word gevra om te vergewe, omdat Hy Hom alreeds in die geskiedenis bewys het (Neh 9:7-31), en omdat die volk sy erfdeel is (1 Kon 8:51).

In vers 11a word die Naam van JHWH as die eintlike rede of motivering vir die gebed om vergifnis gegee. In die bewustheid van sy eie sondige dade kan die bidder hom alleen op die Naam van JHWH beroep. Die Naam van JHWH word op verskillende maniere in die Ou Testament gebruik. Die Deuteronomis het geglo dat God wat in die hemel woon in die tempel teenwoordig is deur sy Goddelike Naam (Weinfeld 1972:193). In die kultus is die Goddelike Naam byvoorbeeld gebruik by die offer, gebed, seën en vloek. Die priesters het die Naam van JHWH oor die Israeliete uitgeroep wanneer hulle seën (Num 6:27), en JHWH se Naam het gefunksioneer tydens die neem van 'n eed (Von Rad 1979:183). Die Naam van JHWH word geassosieer met die groot verlossingsdade van God (Childs 1986:39). Selfs onder die vreemdelinge (vgl 1 Kon 8:42) sou die grote Naam verwys na God se teenwoordigheid en verlossingsmag. JHWH se Naam is in wese $\mathrm{JHWH}$ self soos Hy in sy selfopenbaring teenwoordig is. Sy Naam is nie net die waarborg vir sy teenwoordigheid nie, maar tipeer sy persoonlike betrokkenheid by sy volk (Lev 18:21; Am 2:7; Eseg 36:23) (Van der Woude 1976:957).

Die frase "ter wille van U Naam, JHWH" of slegs "ter wille van U Naam" kom ag keer in die Psalms voor (Ps 23:3; 25:11; 31:4; 79:9; 106:8; 109:21; 143:11). Psalm 25:11 is die enigste verwysing waar die werkwoord סלח (vergewe) saam met die uitdrukking voorkom. In Psalm 79:9 word die uitdrukking wel saam met die Hebreeuse term כפר (versoen) gebruik: "Help 
ons, o God van ons heil, om die eer van u Naam, en red (נצל) ons en doen versoening ${ }^{16}$ (כפר) oor ons sondes ter wille van u Naam"

Psalm 106:8 verwys nie direk na vergifnis of versoening nie maar die gedagte van verlossing of redding (ישע) ter wille van God se Naam word wel hier beskryf.

As die bidder in Psalm 25:11 vergifnis vra ter wille van JHWH se Naam handel dit oor God se eer wat op die spel is. Hierdie uitdrukking wys daarop dat die bidder geen grondmotief vir sondevergifnis by homself vind nie, maar dat die vergifnis van die individu en volk verbind is aan die eer van JHWH self (Van As 1961:47; Bratcher \& Reyburn 1976:233).

Buiten Psalm 25:11 is daar twee ander teksgedeeltes in die סלחgebede waar JHWH se Naam as motivering vir vergifnis weergegee word. In Daniël 9:17-19 word twee keer na JHWH se Naam verwys. JHWH word telkens in hierdie gebed herinner aan die verbondenheid van sy Naam met die stad Jerusalem en sy volk Israel. Numeri 14:15-17 verwys indirek na JHWH se Naam en eer. JHWH word opgeroep tot vergifnis sodat die nasies sy Naam kan grootmaak eerder as om Hom te spot (O'Kennedy \& Olivier 1996:506). Die motivering in Psalm 25:11 is egter uniek omdat JHWH se Naam in kontras tot die groot ongeregtigheid van die bidder staan. Die verwysing na JHWH se Naam staan eerste in die sinskonstruksie en word duidelik beklemtoon. Die groot ongeregtigheid van die bidder staan tweede en is ondergeskik aan JHWH se Naam.

\section{SLOT EN SAMEVATTENDE GEVOLGTREKKINGS}

In die lig van bogenoemde bespreking kan die volgende samevattende gevolgtrekkings gemaak word:

- Psalm 25 is een van vier Psalms waar die Hebreeuse stam o (vergewe) voorkom; gevolglik is hierdie Psalm belangrik vir die verstaan van vergifnis in die Ou Testament.

- Geleerdes is dit eens dat die smeking om vergifnis in vers 11 as die strukturele kern of middelpunt van die gebed beskou kan word.

- Psalm 25 is 'n individuele klaaglied wat waarskynlik as 'n gebed van vertroue of gebed om hulp getipeer kan word. Elemente van die Pentateug

\footnotetext{
${ }^{16}$ Die 1983-AV sowel as die Nuwe Lewende Vertaling (NLV) vertaal die term כפר met "vergewe".
} 
(veral Eks 32-34), die Deuteronomistiese geskiedwerk en wysheidstradisie kom binne hierdie Psalm voor.

- In teenstelling met sommige ander vergifnis-gedeeltes beskou die bidder van Psalm 25 nie sy eie óf die volk se berou as grondrede vir die smeking om Goddelike vergifnis nie. Die bidder wys eerder op sy baie of groot

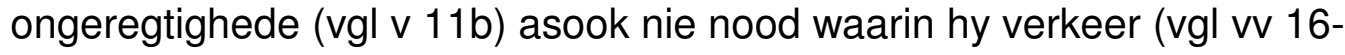
18).

- Die eintlike rede vir die gebed om vergifnis is die Naam of eer van JHWH self. In die bewustheid van sy eie sondige dade kan die bidder hom alleen op die Naam van JHWH beroep. Die frase "ter wille van U Naam, JHWH" kom ag keer in die Psalms voor, maar Psalm 25:11 is die enigste verwysing waar die werkwoord סלח (vergewe) saam met die uitdrukking gebruik word.

- Volgens Psalm 25 is vergifnis nie net die kwytskelding van skuld nie; dit handel oor JHWH se onbegrensde liefde en trou. Vers 11 asook verse 1618 veronderstel dat genade en vergifnis 'n fisiese ingrype van God sal wees. Psalm 25 beklemtoon verder die verband tussen vergifnis en 'n nuwe lewe. Die vergifnis van JHWH maak die nuwe lewe vir die sondaar moontlik.

Navorsing oor Psalm 25 werp nuwe lig op die verstaan van Goddelike vergifnis in die Ou Testament; gevolglik mag hierdie dimensie in die bestudering van Psalm 25 nie afgeskeep word nie.

\section{Literatuurverwysings}

Anderson, A A 1977. The book of the Psalms, Vol 2 (73-150). Greenwood: Attic Press. (NCB.)

Beyerlin, W 1970. Die Rettung der Bedrängten in den Feindpsalmen der Einzelnen auf institutionelle Zusammenhänge untersucht. Göttingen: Van den Hoeck \& Ruprecht.

Bratcher, R G \& Reyburn, W D 1991. A translater's handbook on the Psalms. New York: United Bible Societies.

Brueggemann, W 1991. Bounded by obedience and praise: The Psalms as canon. JSOT 50, 63-92.

Childs, B S 1986. Old Testament theology in canonical context. Philadelphia, PA: Fortress.

Corvin, J W 1973 of 1972. A stylistic and functional study of the prose prayers in the historical narratives of the Old Testament. Ph D Dissertation, Emory University, USA. 
Craigie, P C 1983. Psalms 1-50. Waco, TX: Word Books. (WBC.)

Croft, S J L 1987. The identity of the individual in the Psalms. Sheffield: JSOT Press (JSOTSup 44.)

Eichrodt, W 1967. Theology of the Old Testament, Vol 2, tr by J A Baker. London: SCM.

Fohrer, G 1968. Introduction to the Old Testament, tr by D E Green. New York: Abingdon.

Freedman, D N 1992. Patterns in Psalms 25 and 34, in Ulrich, E et al (eds), Priests, prophets and scribes: Essays on the formation and heritage of the second temple Judaism in honour of Joseph Blenkinsopp, 125-138. Sheffield: JSOT Press. (JSOTSup 149.)

Gerstenberger, E S 1988. Psalms Part 1. Grand Rapids, Ml: Eerdmans. (FOTL 14.)

Greenberg, M I 1983. Biblical prose prayer: As a window to the popular religion of Ancient Israel. Los Angeles, CA: University of California Press.

Gunkel, H 1975. Einleitung in die Psalmen. Dritte Auflage. Göttingen: Van den Hoeck \& Ruprecht.

Hausmann, J 1986. s v סלח. TWAT 5, 859-867.

Human, D J 1994. Reading the texts of the Bible: Wth illustrative reference to Psalm 25. Scriptura 49, 88-96.

Human, D J 1996. The tradition-historical setting of Psalm 25: How wisdom motives contribute to its understanding. Skrif en Kerk 17(1), 76-88.

Knierim, R 1976. s v עון. THAT2, 221-223.

Kraus, H J 1993. Psalms 1-59: A continental commentary, tr by H C Oswald. Minneapolis, MN: Fortress Press.

Kselman, J S 1992. s v Forgiveness (OT). ABD 2, 831-833.

Kunz, J K 1977. The retribution motif in Psalmic wisdom. ZAW 89, 223-233.

Louw, P U 1979. Gebed in die Ou Testament: 'n Studie van die grondbetekenis en liggaamsbelewing in die gebed. M Th-tesis, Universiteit van Stellenbosch.

Mays, J L 1994. Psalms. Louisville, KY: John Knox.

McCann, J C 1996. The book of the Psalms, in Keck, L E et al (eds), The New Interpreter's Bible Vol 4, 639-1280. Nashville, TN: Abingdon.

McKeating, H 1965. Divine forgiveness in the Psalms. Scottish Journal of Theology 18, 69-83.

Möller, H 1932. Strophenbau der Psalmen. ZAW50, 240-256.

O'Kennedy, D F \& Olivier, J P J 1996. Die konsep vergifnis in die Ou Testament. NGTT 37(4), 496-508.

Olivier, J P J 1997. s v סלח. NIDOTTE 3, 259-264.

Ridderbos, J 1955. De Psalmen, I. Kampen: Kok. (COT.)

Ridderbos, N H 1962. De Psalmen. Kampen: Kok. (KV.)

Ruppert, L 1972. Psalm 25 und die Grenze der kultorientierten Psalmexegese. ZAW 84, 576-582.

Schultz, C 1981. s v עוה. TWOT2, 650-652.

Stamm, J J 1940. Erlösen und vergeben im Alten Testament. Bern: A Francke.

Terrien, S 2003. The Psalms: Strophic structure and theological commentary. Grand Rapids, MI: Eerdmans. (Eerdmans Critical Commentary.)

Van As, J J 1961. Skuldbelydenis en genadeverkondiging in die Ou Testament. Utrecht: Elinkwijk. 
Van der Lugt, P 2006. Cantos and strophes in biblical Hebrew Poetry, with special reference to the first book of the Psalter. Leiden: Brill. (OTS 53.)

Van der Woude, A S 1976. s v שם. THAT2, 935-963.

Van Uchelen, N A 1979. Psalmen I. Nijkerk: G F Callenbach. (POT.)

Von Rad, G 1979. Old Testament theology, Vol 1. 3rd impression. London: SCM.

Weinfeld, M 1972. Deuteronomy and the Deuteronomic School. Oxford: Clarendon Press.

Weiser, A 1965. The Psalms, tr by H Hartwell. 2nd Impression. London: SCM.

Westermann, C 1989. The living Psalms. Grand Rapids, MI: Eerdmans. 